\title{
Stammbuch Ludwig Karl Ludwig
}

Im Februar 2013 konnte die Württembergische Landesbibliothek das Stammbuch des Darmstädter Juristen Ludwig Karl Ludwig (1773-1860) aus der Zeit der Französischen Revolution erstehen. Das Freundschaftsalbum, das aus Privatbesitz stammt, ist in mehrfacher Hinsicht ein zeit- und kulturgeschichtlich wertvolles Dokument. Es gewährt Einblicke in das zu Studienzeiten des Stammbuchhalters geknüpfte Netzwerk während einer Phase großer politischer und sozialer Umbrüche auch in Deutschland und weist durch die nachträglichen Notizen des Stammbuchhalters zum weiteren Schicksal der Beiträger weit über die relativ kurze Laufzeit des Albums (1791 bis 1797) hinaus. Der weitaus größte Teil der Beiträge stammt aus der Universitätsstadt Gießen, und auch die anderen Eintragungsorte (u.a. Erlangen, Würzburg und Darmstadt) sind nicht in Württemberg angesiedelt.

Dennoch erweist sich das Büchlein als wichtige Ergänzung für die Sammlungen der Württembergischen Landesbibliothek: Die Einträge von zwei engen Freunden Hölderlins, Friedrich Joseph Emerich und Philipp Siegfried Schmid, machen das unter der Signatur Cod. hist. $8^{\circ} 341$ in der Handschriftenabteilung verwahrte Stück auch zu einer hochwillkommenen Ergänzung der Bestände des Hölderlin-Archivs. Wenngleich ihre in Gießen erfolgten Einträge (Emerich: Nr. 52 vom Mai 1792, 346b vom September 1792 sowie Schmidt: Nr. 47 vom 17.5.1792) lediglich die für Stammbücher typischen Lebensweisheiten widerspiegeln, sind sie aufgrund des persönlichen und lokalen Umfeldes beachtenswert. Beide Personen zählen zum jakobinisch-republikanischen Freundeskreis Hölderlins. Die zeitliche Nähe der Einträge wie auch ihre relative Nachbarschaft innerhalb des Stammbuches lassen vermuten, dass sich die beiden Freunde Hölderlins bereits im Mai 1792 kennengelernt haben.

Friedrich Joseph Emerich (1773-1802) stammte aus einer alteingesessenen Wetzlarer Kameralfamilie und absolvierte in Mainz und Marburg ab
1790 ein Jurastudium. Während seines Aufenthalts als Jurist in Wetzlar von 1793-1796 engagierte sich Emerich schon aktiv für jakobinische Ideen und gehörte dem Wetzlarer Bund „Freunde der Wahrheit" an, was schließlich ein Berufsverbot als Advokat nach sich zog. Im März 1795 war dieser Bund auch in Jena tätig. Dort hatte er bei einer geheimen nächtlichen Zusammenkunft möglicherweise bereits über Isaak Sinclair oder Johann Hugo Wyttenbach auch Friedrich Hölderlin kennengelernt. Ein Beleg dafür mag die Beschreibung einer Figur aus dem "Hyperion" sein, die gewisse Züge Emerichs trägt (vgl. Hyperion, StA Bd. 3, S. 32f.). 1796-1797 schloss sich Emerich französischen Truppen an und war von 1798-1801 Verwaltungsbeamter der französischen Regierung in Mainz. Klar belegt ist dort ein Treffen zwischen Hölderlin und Emerich im Jahre 1799. Hölderlin war im Zusammenhang mit seinem „Iduna“-Projekt dort, wo er nicht nur Kontakt mit inm aufnahm, sondern sich auch intensiv mit dessen literarischem Werk beschäftigte: "Ich hab' es versucht, in eines von Emerichs Gedichten etwas mehr Einfachheit und Harmonie zu bringen. Seine Gedichte enthalten, wie Du finden wirst zum Theil treffliche Gedanken..." (an Neuffer, Juli 1799).

Wenige Zeit vor dem Mainzer Treffen mit Emerich machte Hölderlin in Frankfurt die Bekanntschaft mit dem aus Friedberg stammenden Theologen und Schriftsteller Philipp Siegfried Schmid (17741859). Es gibt auffallende Parallelen im Leben von Hölderlin und Schmid bis hin zur späteren psychischen Erkrankung. Schmid nahm ebenfalls ein Studium der Theologie auf und immatrikulierte sich 1792 in Gießen. Aus seiner ersten Studienzeit stammt auch der Eintrag im Stammbuch Ludwig. Schon bald wechselte er nach Jena, wo auch Hölderlin zeitweise lebte. Beide waren dort mit Isaak von Sinclair und Jakob Zwilling befreundet, haben sich dort jedoch vermutlich noch nicht getroffen, zumal Schmid schon bald nach der Ankunft Hölderlins Jena verließ und nach Friedberg zurückkehrte. Anstelle des vom Vater erhofften 
Pfarramts widmete sich Schmid seinen dichterischen Arbeiten. Während Schiller diese lobte, ging Goethe, den Hölderlin und Schmid beide in Frankfurt aufsuchten, auf Distanz - auch hier eine auffallende Parallele zwischen innen. Bei dieser Gelegenheit entstand eine mehrjährige Freundschaft, dokumentiert durch einen bis 1801 dauernden intensiven Briefwechsel. Durch den Eintritt Siegfried Schmids in den Militärdienst trennten sich zeitweise ihre Wege, nachdem er Hölderlin seinen „potentiellen Nachlass“ zur Veröffentlichung anvertraut hatte. Dieser bezog Schmid wiederum bei den Journalplänen zur "Iduna" mit ein, die aber letztlich scheiterten, ebenso wie ein Universitätsamt, das beide kurzfristig anstrebten, hier aber nicht mehr auf die Unterstützung Schillers zählen konnten. Das geistige Gespräch zwischen ihnen gipfelte schließlich in Hölderlins Elegie "Stutgard" von 1801, das er Siegfried Schmid widmete: „Und was uns der himmlische Tag zu sagen geboten, / Das zu nennen, mein Schmid! reichen wir beide nicht aus." (StA Bd. 2,1, S. 89,v. 99f.).
Dicke: $4 \mathrm{~cm}$ ) gestaltete Büchlein umfasst 207 Blätter, auf denen sich insgesamt 293 Einträge finden, und verfügt am Schluss über ein ebenfalls handschriftliches Register der Beiträger von 21 Seiten Umfang. 5 Blätter des Gesamtvolumens sind im Laufe der Zeit nachweislich verlorengegangen.

Der Einband ist stark beschädigt, der Buchblock wird jedoch durch eine mit Buntpapier bezogene Papphülse geschützt. Am Einband selbst fehlen der Rücken und der originale hintere Deckel. Der Vorderdeckel liegt lose bei, der Deckel eines anderen, hochformatig ausgerichteten Buches gleicher Größe dient als Ersatz für den fehlenden hinteren Deckel. Anhand des erhalten gebliebenen Vorderdeckels kann man sich ein Bild von der schlichten Eleganz des ursprünglichen Einbandes machen. Es handelt sich um Pappe, die mit braunem Leder überzogen wurde. Verziert ist der Ledereinband mit einem aus goldgeprägten Linien gebildeten Rahmen, in dessen vier Ecken sich je ein kleiner goldener Stern befindet. Die Kanten der

Deckel sind mit winzigen Prägestempeln verziert, der Schnitt des Buches vergoldet. Spiegel und Vorsatz sind aus Marmorbuntpapier gefertigt, dessen vorherrschende Farbe blau ist. Das Bändchen einerseits vor weiteren Schäden zu bewahren und andererseits seinen Originalzustand trotz der verlorengegangenen Teile so gut wie möglich zu erhalten und sichtbar zu machen, wird eines Tages Aufgabe behutsamer restauratorischkonservatorischer Maßnahmen sein.

Der Vorbesitzer, Herr Jochen Wiedemann, hat die Ergebnisse seiner umfangreichen Forschungen zu diesem Stammbuch freundlicherweise der WLB mitgeteilt. Ihm ist es somit zu verdanken, dass die Bibliothek bereits unmittelbar nach der Erwerbung des Stückes in der Lage ist, künftigen Benutzern zahlreiche inhaltliche Informationen, die über die von der Bibliothek zu leistende reguläre Erschließung weit hinausgehen, zur Verfügung zu stellen. Das in Queroktav (Breite: 17,5 cm; Höhe: 10, 5 cm;
Ausgestattet ist das Album mit zeit- und gattungstypischem Schmuck: Es enthält 9 ScherenschnittSilhouetten, z.T. kolorierte Federzeichnungen, einen Kupferstich (Stadtansicht von Erlangen), und verschiedene Miniaturen (Aquarelle und Deckfarbenmalereien) sowie zwei mit Motiven und Sinnsprüchen bestickte Seidenstoffe, die beide von weiblichen Beiträgern stammen.

Jörg Ennen, Kerstin Losert 